\title{
Novel graphite rod electrode modified with iron- functionalized nanozeolite for efficient wastewater treatment by microbial fuel cells
}

Mostafa Hassani ${ }^{\mathrm{a}}$, Mohsen Zeeb ${ }^{\text {** }}$, Amirhossein Monzavi ${ }^{\mathrm{b}}$, Zahra Khodadadia and Mohammad Reza Kalaee ${ }^{\mathrm{c}, \mathrm{d}}$ ${ }^{a}$ Department of Applied Chemistry, Faculty of Science, Islamic Azad University, South Tehran Branch, Tehran, Iran ${ }^{b}$ Department of Polymer and Textile Engineering, Islamic Azad University, South Tehran Branch, Tehran, Iran

${ }^{c}$ Department of Polymer Engineering, Islamic Azad University, South Tehran Branch, Tehran, Iran

${ }^{d}$ Nanotechnology Research Center, Islamic Azad University, South Tehran Branch, Tehran, Iran

\section{A R T I C L E I N F O :}

Received 10 Nov 2020

Revised form 14 Jan 2021

Accepted 23 Feb 2021

Available online 29 Mar 2021

\section{Keywords:}

Microbial Fuel Cells (MFCs),

Graphite electrodes,

Iron-functionalized ZSM-5 nanozeolit, Wastewater treatment

\begin{abstract}
A B S T R A C T
Microbial fuel cells (MFCs) are a green and efficient approach to treat wastewater and generate energy. According to the present research, a novel MFC fabricate based on graphite rod electrodes (GRE). The surface of this cathode was modified with iron-functionalized ZSM5 nanozeolite. The characterization of Iron doping in nanozeolite structure and electrode surface modification were obtained by XRD and EDX analyzes, respectively. Chemical analysis of square wave (Sqw) and cyclic voltammetry (CV) determined for all of three graphite electrodes (G, G-Z and G-Z/Fe) with higher efficiency. Morover, the comparison of experimental results from 72-hour fuel cell steering was evaluated and showed that the G-Z/Fe graphite electrodes has maximum efficiency and effectiveness. Thus, the efficiency of fuel cell output current and residual chemical oxygen demand removal with this electrode increased up to $21.8 \%$ and $36.9 \%$, respectively. The effiucient recovery for the modification of the graphite electrode surface was achieved due to increasing of the specific surface area, the active sites of functionalized nanozeolite and the elevation in the electrical conductivity through the presence of iron particles doped in the ZSM-5/Fe nanocatalyst structure. Therefore, the G-Z/Fe cathode can be used as a favorite electrode for the construction of MFCs based on GRE with high efficiency and economic.
\end{abstract}

\section{Introduction}

Microbial fuel cell (MFC) has different approach for wastewater treatment because the wastewater treatment process generates electricity or hydrogen gas instead of consuming electricity [1]. The MFC technology is depended on generating bioelectricity from bacterial biomass as the latest

\footnotetext{
*Corresponding Author: Mohsen Zeeb

Email: zeeb.mohsen@gmail.com

https://doi.org/10.24200/amecj.v4.i01.133
}

method for wastewater treatment. MFCs can divided into two main categories, mediated and unmediated groups. The MFCs separated the compartments of the anode (oxidation) and the cathode (reduction). Most of MFCs use an organic electron donor that is oxidized to produce $\mathrm{CO}_{2}$, protons, and electrons. The cathode acts by different electron acceptors such as oxygen $\left(\mathrm{O}_{2}\right)$. Other electron acceptors studied for metal treatment by reduction, nitrate reduction, and sulfate reduction in $25{ }^{\circ} \mathrm{C}$ and $\mathrm{pH}$ of 7 [2-4]. Microorganisms within an 
MFC, can be decomposed the organic matter by oxidizing, produce electrons that pass through a series of respiratory enzymes inside the cell and produce energy for the cell in the form of ATP. Then. the electrons are released towards a final electron acceptor. This receptor captures and reduces the electrons. For example, oxygen can be converted to water by the catalytic reaction of electrons with proton [5]. Previous research on electrodes used catalytic adhesives, carbon with non-platinum catalysts, flat carbon, carboncoated tube and bio electrodes in the fabrication of carbon-based cathodes. Therefore, this study employed a carbon rod electrode coated with ZSM5/Fe nanocatalyst [6-8]. Zeolites are tetrahedral crystalline aluminosilicates bonded with oxygen bridges. Due to their SSA, the specific channel structure, high thermal and hydrothermal stability, they are widely used in industries such as chemistry and petrochemicals, and water and wastewater treatment [9-11]. As mentioned, extensive research has been performed throughout the world to make fuel cells exploiting new electrodes. The researchers developed a cathode made of nickel-doped reduced nanographene as well as acid-hydroionized reduced nanographene to determine and evaluate the efficiency of the power output density with each of these electrodes. According to the results, the acid-hydroionized reduced nanographene showed the higher power output density (37\%) than the nickel-doped reduced nanographene [12]. In another study, the researchers were developed a triple nanocomposite cathode containing graphene oxide, polyethylene dioxythiophene and iron oxide nanorods to increase the current efficiency of MFCs. Due to the large specific surface area of the electrode, high electrical conductivity as well as large sites for oxygen uptake in this electrode, the oxidation-reduction reaction occurs very quickly; as far as the power output density of the cell could be maintained for more than 600 hours [13]. By previous studies, a cathode was made of carbon nanotubes doped with titanium oxide nanoparticles aimed at enhancing the current output density and increasing the elimination of residual chemical oxygen demand (COD). The results of this study revealed an increase in the specific surface area and the active sites for oxygen uptake, so that the maximum current output density produced was $15.16 \mathrm{~mW} \mathrm{~m}^{-2}$ and the COD removal efficiency was reported between 54-71\% (after 10 days), which was related to the presence of active reaction sites on the electrode [14]. The results showed us, the specific surface area is a very effective factor in increasing the efficiency of MFCs.

In this study, the graphite rod as a high stability and electrical conductivity was used for wastewater treatment. So, the surface modification of graphite rod by zeolite nanocatalyst will increase the specific surface area of the electrode. On the other hand, the modification of graphite rods with zeolite nanocatalyst were compared to simple graphite rod with the low price and poor efficiency [15, 16]. Metal nanoparticles can greatly influence the oxygen reduction [17-22]. Hence, in this study the graphite rod electrodes were modified with iron particles $(\mathrm{Fe})$ as a doping agent on ZSM-5 nanozeolite (G-Z/Fe/ ZSM-5) for increasing of MFC efficiency for wastewater treatment.

\section{Experimental}

\subsection{Material}

The ZSM-5 nanocatalyst powder (from the Zeolites family) was purchased from Sigma Aldrich with a crystal size of $0.5 \mu \mathrm{m}$ and a pore size of $5.5 \mathrm{~A}^{0}$. Ferric chloride $\left(\mathrm{FeCl}_{3}\right)$, the potassium chloride ( $\mathrm{KCl}$ ), the sodium di-hydrogen phosphate dihydrate $\left(\mathrm{NaH}_{2} \mathrm{PO} 4.2 \mathrm{H}_{2} \mathrm{O}\right)$, di-sodium hydrogen phosphate dihydrate $\left(\mathrm{Na}_{2} \mathrm{HPO}_{4} \cdot 2 \mathrm{H}_{2} \mathrm{O}\right)$, the ammonium chloride $\left(\mathrm{NH}_{4} \mathrm{Cl}\right)$ and sulfuric acid $\left(\mathrm{H}_{2} \mathrm{SO} 4\right.$, $\% 98$ ) were also purchased from Merck Germany. Nafion 117 membrane (DuPont, the USA) was used to Preparation the cell.

\subsection{Preparation of ZSM-5/Fe Nanocatalyst}

To Preparation the functionalized ZSM-5 nanocatalyst, first $2.5 \mathrm{~g}$ of ZSM-5 nanozeolite powder was placed in the furnace at a temperature of $500^{\circ} \mathrm{C}$ for 4 hours and calcined. Then, $0.5 \mathrm{~g}$ of ferric chloride $\left(\mathrm{FeCl}_{3}\right)$ powder was dissolved in 

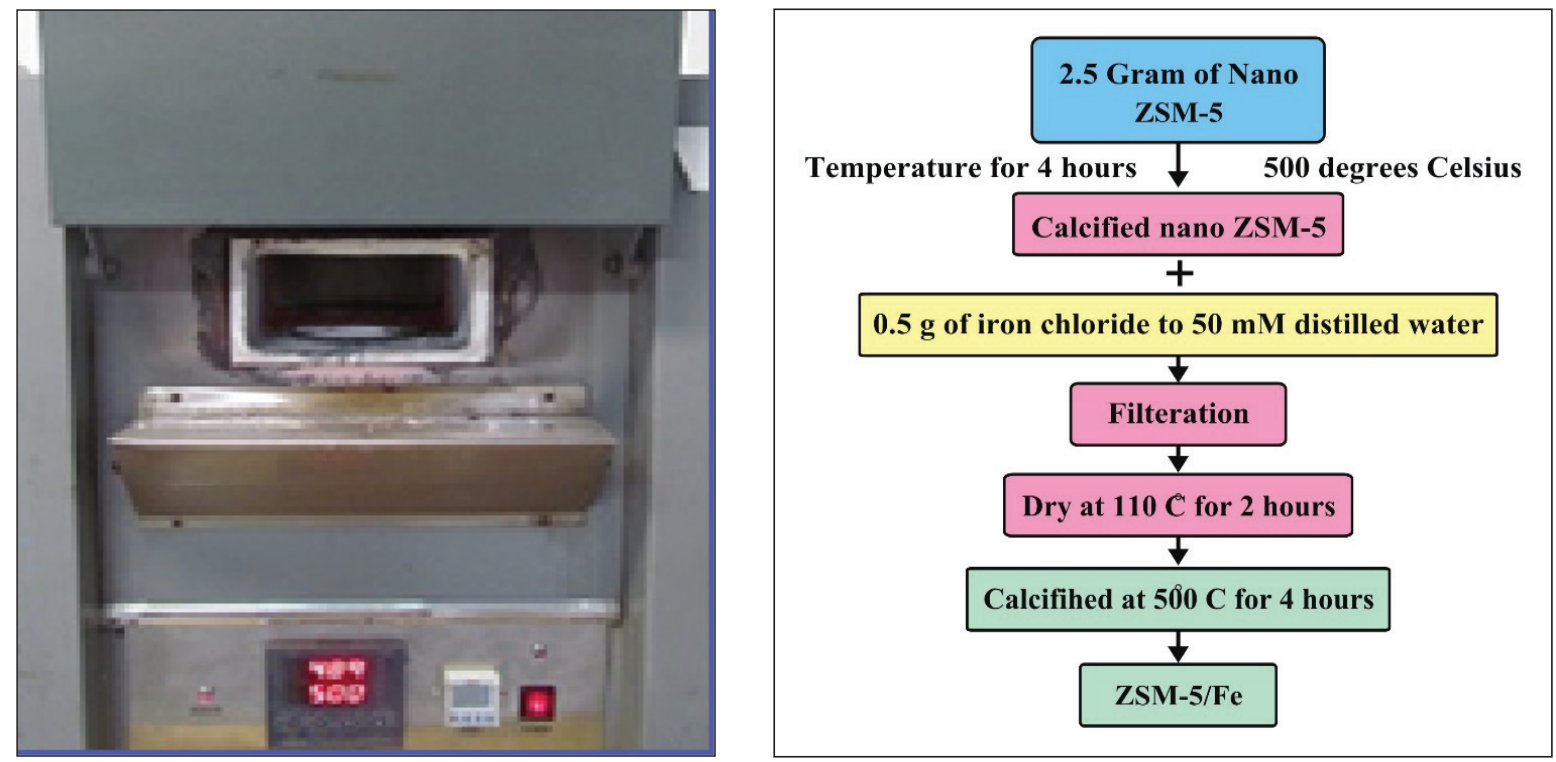

Fig.1. Schematic of the preparation process and calcination of ZSM-5/Fe nanocatalyst

distilled water twice for one hour, added to the calcined ZSM-5 nanozeolite powder and mixed for another 30 minutes, and filtered with a filter paper. The resulting powder was rinsed three times with distilled water and placed in an oven at a temperature of $80^{\circ} \mathrm{C}$ for 2 hours. Next, the powder was separated from the filter paper and re-calcined at a temperature of $500^{\circ} \mathrm{C}$ for 4 hours. The method of preparation above nanocatalyst is schematically illustrated in Figure1.

\subsection{Characterization}

X-ray diffraction (XRD, STADI-P, the USA) was used to investigate ferrous $(\mathrm{Fe})$ metal in the nanocatalyst structure functionalized with these metal. Brunauer-Emmett-Teller (BET) surface area analysis (Belsorb apparatus, Japan) was used to determine the SSA of nanocatalyst particles, and energy-dispersive X-ray spectroscopy (EDX, MIRA III SAMX, Czech Republic) were applied to investigate the surface modification of the graphite electrode by each of the nanocatalysts.

\subsection{Electrode Modification}

To modify the graphite surface and to impregnate with the synthesized nanocatalyst powders, $0.5 \mathrm{~g}$ of each of the produced nanocatalysts (ZSM-5, ZSM-5/Fe) was poured into a test tube and $10 \mathrm{ml}$ of ethanol was added and the graphite electrode was inserted into the test tube and placed in an

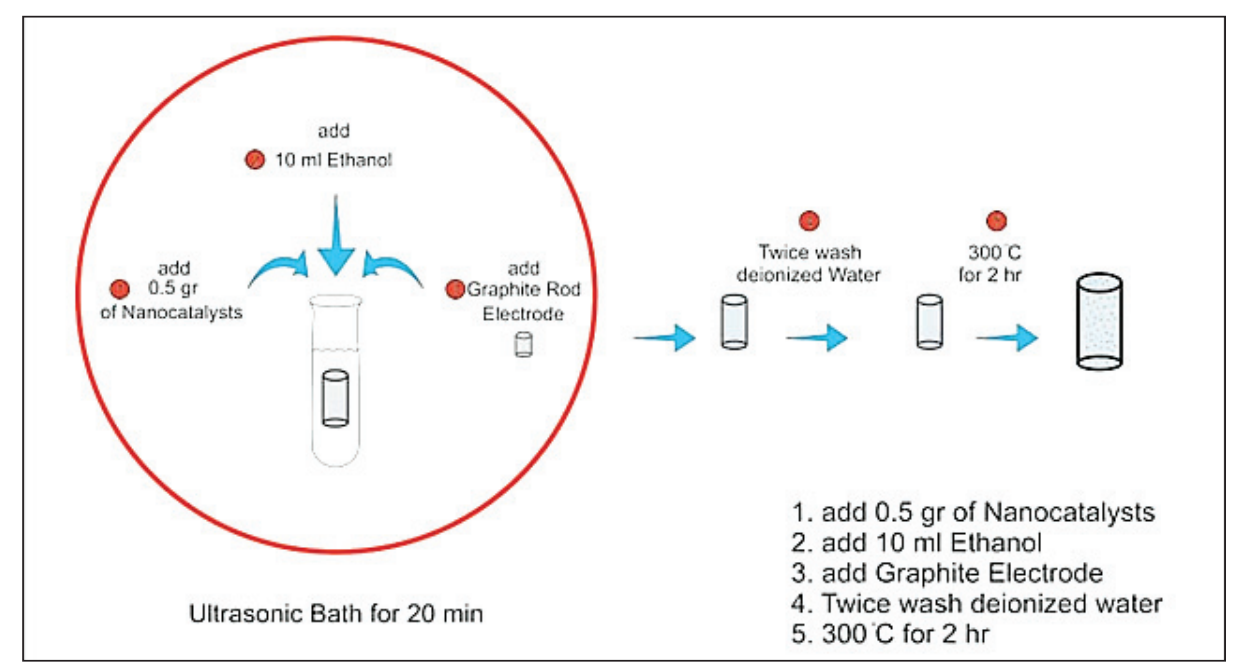

Fig. 2. Schematic of electrode surface modification by ZSM-5/Fe nanocatalyst 
ultrasonic bath for 20 minutes. Then, the resulting electrode was rinsed twice with deionized water and placed in a furnace at a temperature of $300^{\circ} \mathrm{C}$ for 2 hours (Fig.2).

\subsection{MFC construction and operation}

This study applied with a separate two-part cell consisting of anaerobic anode and aerobic cathode. The chambers were made based on $500 \mathrm{~mL}$ pyrex glass with $75 \%$ of the volume as a working volume (375 mL). The two chambers were separated by a pyrex tube with an inner diameter of $0.8 \mathrm{~cm}$ and a length of $13.4 \mathrm{~cm}$ embedded in the middle portion with the proton exchange Nafion 117 membrane. The electrodes were made with rod graphite and heated at $3000^{\circ} \mathrm{C}$ with an area of $22.62 \mathrm{~cm}^{2}$. In order to remove any impurities and improve membrane performance, the membrane was first boiled for an hour in $3 \% \mathrm{H}_{2} \mathrm{O}_{2}$ and then washed in $1 \mathrm{M}$ sulfuric acid for 1 hour. Oxygen gas was injected into the cathode with a sparger at a flow rate of 20 $\mathrm{ml} \mathrm{min}^{-1}$, and nitrogen gas was injected into the anode chamber to provide anaerobic conditions. A magnetic stirrer was used to stir the solutions inside the anode and cathode chambers, and a copper wire was used to bond the anode and the cathode electrodes. Acidification of the medium inhibits the optimal growth of the bacteria in the anode chamber, so it is necessary to use a buffer with appropriate $\mathrm{pH}$ in the bacterial growth medium. For this purpose, in order to maintain the acid strength in the cell, $50 \mathrm{mM}$ of phosphate buffered solution (PBS) (0.13 $\mathrm{g} \mathrm{L}^{-1}$ of potassium chloride, $3.32 \mathrm{~g} \mathrm{~L}^{-1}$ of sodium di-hydrogen phosphate dihydrate, $5.13 \mathrm{~g}$ $\mathrm{L}^{-1}$ of di-sodium hydrogen phosphate dihydrate, and $0.31 \mathrm{~g} \mathrm{~L}^{-1}$ of ammonium chloride) was prepared in the cathode chamber and $375 \mathrm{~mL}$ was poured into the cathode chamber [23].

\subsection{Microorganisms}

In the anodic chamber of the fuel cell, the anaerobic wastewater prepared from the industrial town treatment plant was used as inoculum. The samples from the treatment plant were stored in stainless steel containers at $4^{\circ} \mathrm{C}$, and transferred to the laboratory. The combined inoculum was inoculated into the pre-prepared culture medium containing $1 \mathrm{~g} \mathrm{~L}^{-1}$ of glucose, $3 \mathrm{~g} \mathrm{~L}^{-1}$ of yeast extract, $11 \mathrm{~g}$ $\mathrm{L}^{-1}$ of peptone, $0.5 \mathrm{~g} \mathrm{~L}^{-1}$ of ammonium chloride [24]. During the experiments, the cells were kept at room temperature and stirred at $50 \mathrm{rpm}$ for 72 hours (Table 1).

\subsection{Analytical method}

A multimeter (MASTECH MS8360G, China) was used to measure the output voltage of the cell. The residual COD of the samples was measured with COD meter (Model 76133, Aqua Litik, Germany). Three-electrode systems including, anode electrode

Table.1. Anaerobic wastewater profile for anode chamber of fabricated fuel cell in the present study

\begin{tabular}{lll}
\hline Parametrs & Scale & Unit \\
\hline $\mathrm{T}$ & $22 / 81$ & ${ }^{\circ} \mathrm{C}$ \\
$\mathrm{pH}$ & $7 / 13$ & --- \\
$\mathrm{SV} 1$ & 1159 & $\mathrm{mg} \mathrm{L}^{-1}$ \\
$\mathrm{MLSS}$ & 2076 & $\mathrm{mg} \mathrm{L}^{-1}$ \\
$\mathrm{COD}$ & 1216 & $\mathrm{mg} \mathrm{L}^{-1}$ \\
BODs & 505 & $\mathrm{mg} \mathrm{L}^{-1}$ \\
DO & 0.6 & $\mathrm{mg} \mathrm{L}^{-1}$ \\
Total Coliform & 9000 & $\left(\mathrm{MPN}^{-100 \mathrm{~mL})}\right.$ \\
\hline
\end{tabular}


(modified electrodes), platinum wire electrode, and silver/silver chloride electrode (as the working electrode) were used to electrochemically measure the made electrodes. Cyclic voltammetry (CV) and square wave voltammetry ( $\mathrm{Sqw}$ ) with scanning rate of $5 \mathrm{mV} \cdot \mathrm{s}^{-1}$ in $50 \mathrm{mM}$ phosphate buffered solution (PBS) (Palmsense 3, the Netherlands) were used to investigate the electrochemical behaviors of the electrodes.

Spectrophotometric method was used to examine the treated wastewater. Initially, standard solutions with concentrations of 100-800 with 3 $\mathrm{ml}$ of digestion solution (containing potassium dichromate, sulfuric acid and silver sulfate) and $7 \mathrm{ml}$ of stock solution (potassium hydrogen phethalate) are prepared and placed in an oven at $150^{\circ} \mathrm{C}$ for 1.5 hours was placed. After cooling, it was placed in a spectrophotometer $(600 \mathrm{~nm})$ and the calibration curve was drawn. It was measured by placing the absorbance of the unknown sample in the residual COD calibration equation.

\section{Results and Discussion}

\subsection{BET characterization}

By comparing the as, BET parameter as in Figure 3 and the results in Table 2, in each of the four BET analysis curves of the nanocatalysts, the highest SSA was related to the catalyst functionalized with Fe metal (ZSM-5/Fe, which was determined to be $\left.408.41 \mathrm{~m}^{2} \mathrm{~g}^{-1}\right)$.

\subsection{X-Ray Diffraction (XRD) analysis}

The XRD spectrum for the ZSM-5 and the ZSM-5/ Fe nanocatalyst was shown in Figure 4. The ZSM$5 / \mathrm{Fe}$ nanocatalyst confirms the presence of iron particles doped with silicate particles (Fig. 4).
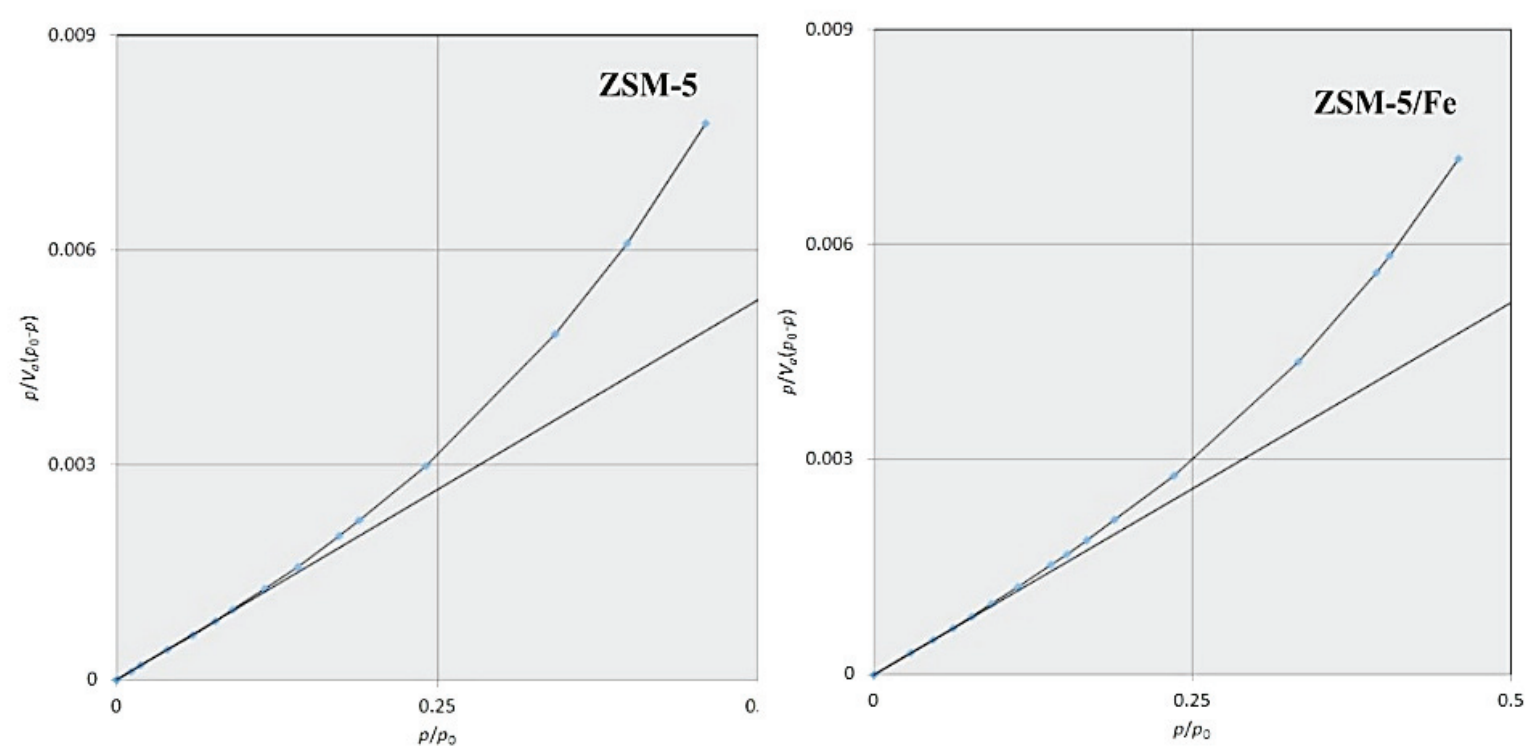

Fig.3. BET curves of prepared nanocatalysts

Table 2. specific surface area of prepared nanocatalysts

\begin{tabular}{llll}
\hline Row & Nanocatalysts & BET & Unit \\
\hline 1 & ZSM-5 & 374.66 & $\mathrm{~m}^{2} \mathrm{~g}^{-1}$ \\
2 & ZSM-5/Fe & 408.41 & $\mathrm{~m}^{2} \mathrm{~g}^{-1}$ \\
\hline
\end{tabular}




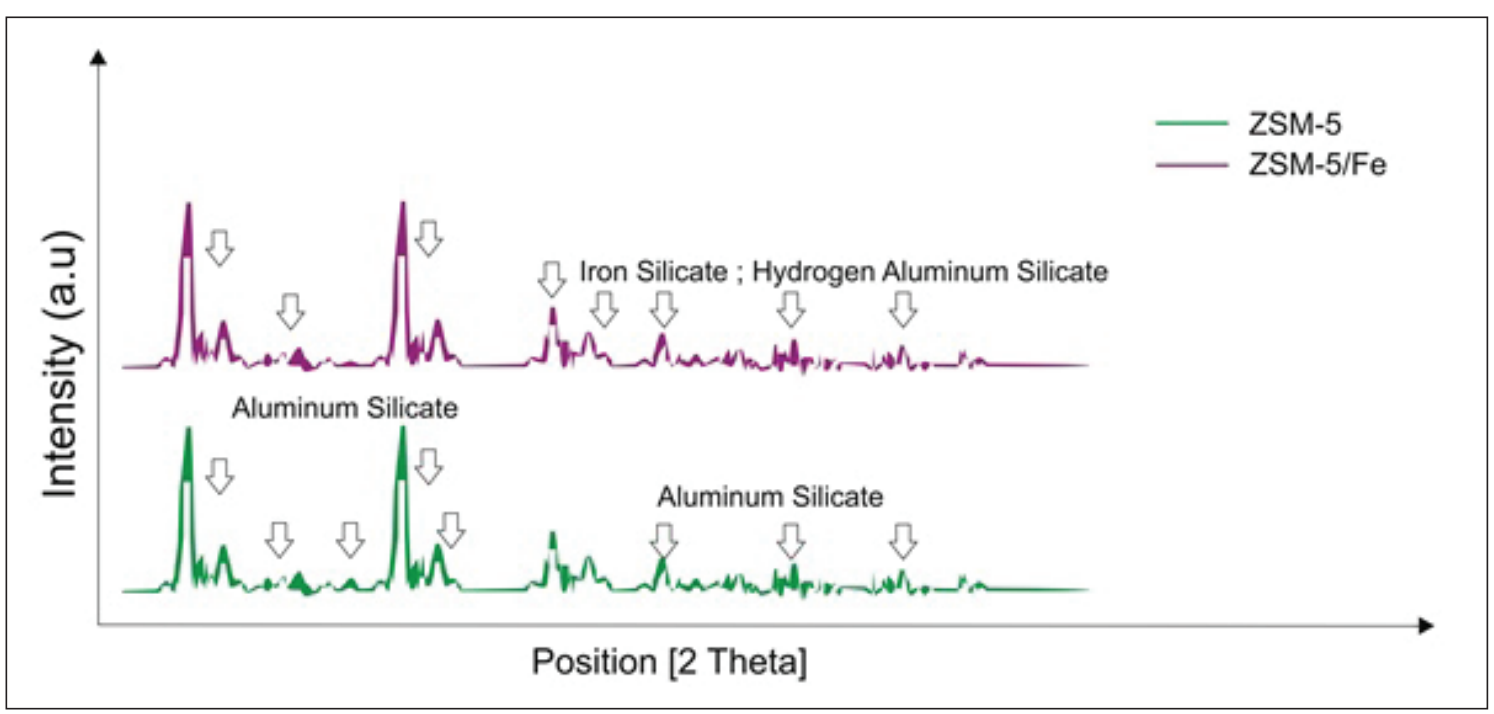

Fig. 4. X-ray diffraction (XRD) analysis of nanocatalysts, ZSM-5 and ZSM-5/Fe.

\subsection{Energy dispersive $X$-ray spectroscopy (EDX)} analysis

The curves of EDX analyzes for the surface of G-Z and G-Z/Fe electrodes compared as Figure $5 \mathrm{a}$ and $5 \mathrm{~b}$. The EDX analyzes showed the presence of doped iron particles (in $1 \mathrm{Kev}$ area in the second curve). The presence of alumina and silicate peaks in both curves confirms that the surface of the electrodes has been covered by nanocatalysts.
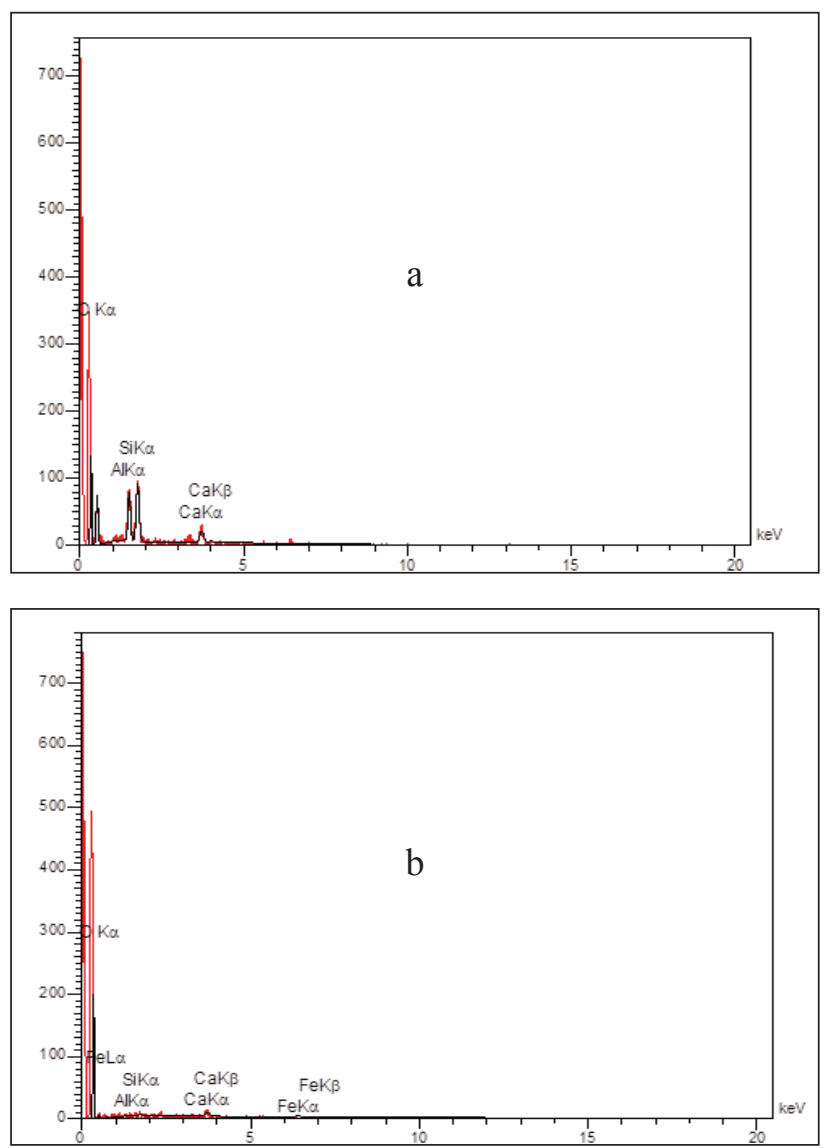

Fig.5. Energy-dispersive X-ray spectroscopy (EDX) analysis of the surface modified electrodes (a) G-Z; (b) G-Z/Fe 


\subsection{Electrochemical characterization}

Comparing the cyclic voltammetry $(\mathrm{CV})$ cerves for G, G-Z and G-Z/Fe was shown in Figure 6a, $6 b$ and $6 \mathrm{c}$. The peak of the graphite electrode modified with iron-doped nanocatalyst (ZSM-5/Fe), which has a higher specific surface area, has the maximum current compared to other electrodes. Due to Figure 7 , the square wave (Sqw) voltammetric peaks of the G, GZ-5 and GZ-5/Fe electrodes, with the scan rate of $5 \mathrm{mV} \cdot \mathrm{s}^{-1}$ in $50 \mathrm{mM}$ phosphate-buffered saline (PBS) at an ambient temperature and in the potential range of 1 to 90 volts were compared. Comparing the electrode peaks, the G-Z/Fe electrode peak has the highest current $\left(3500 \mu \mathrm{A} \mathrm{cm}^{-2}\right)$ relative to other electrodes. The graphite electrode peak has the lowest current $\left(2000 \mu \mathrm{A} \mathrm{cm}^{-2}\right)$, which indicates that the ZSM-5 nanocatalyst doped with iron caused to increase the current of analysis.
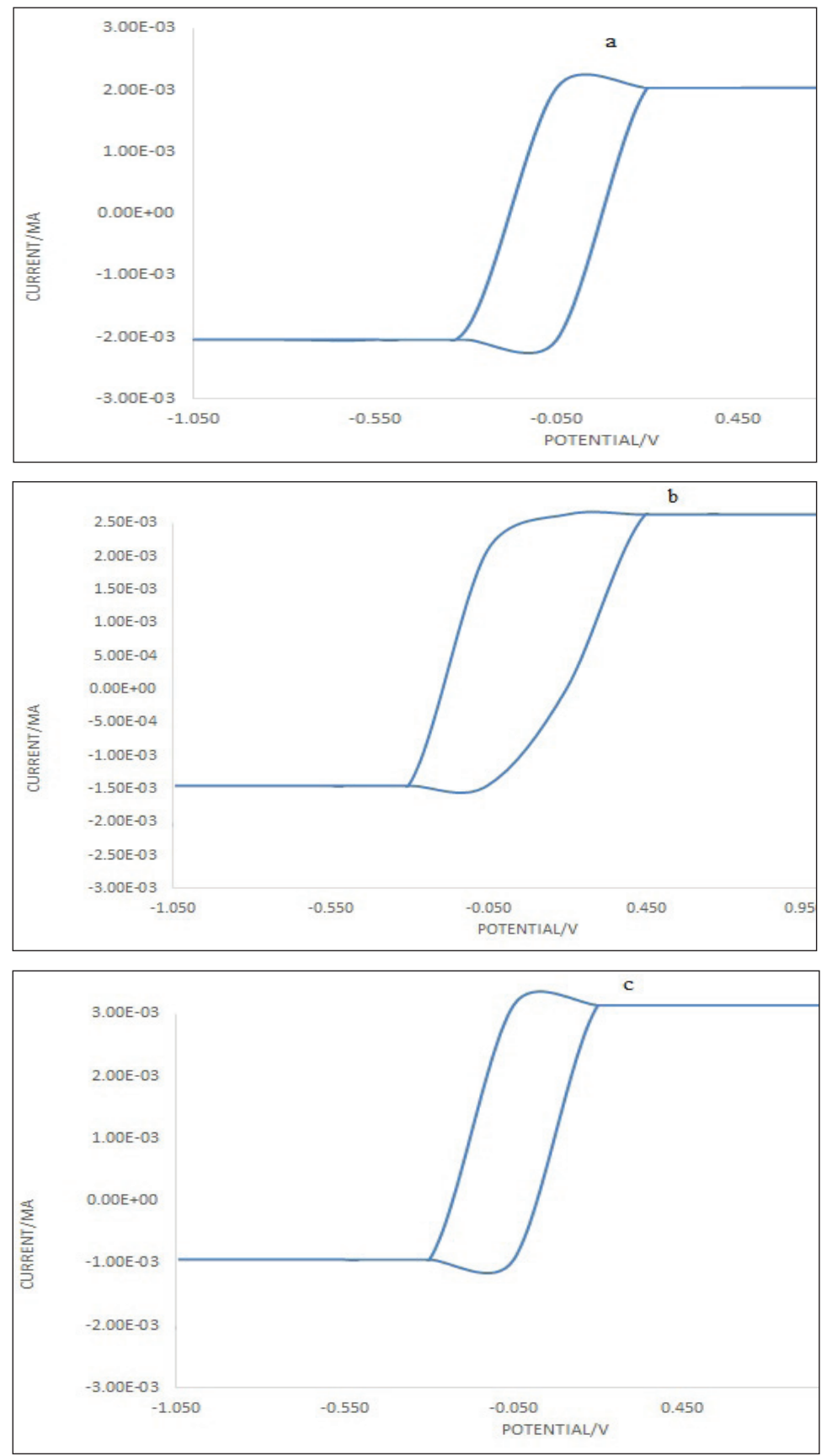

Fig. 6. Cyclic voltammetry (CV) analysis of electrodes prepared in $50 \mathrm{mM}$ phosphate buffered solution (PBS) in room temperature. (a)G, (b)G-Z, (c)G-Z/Fe 


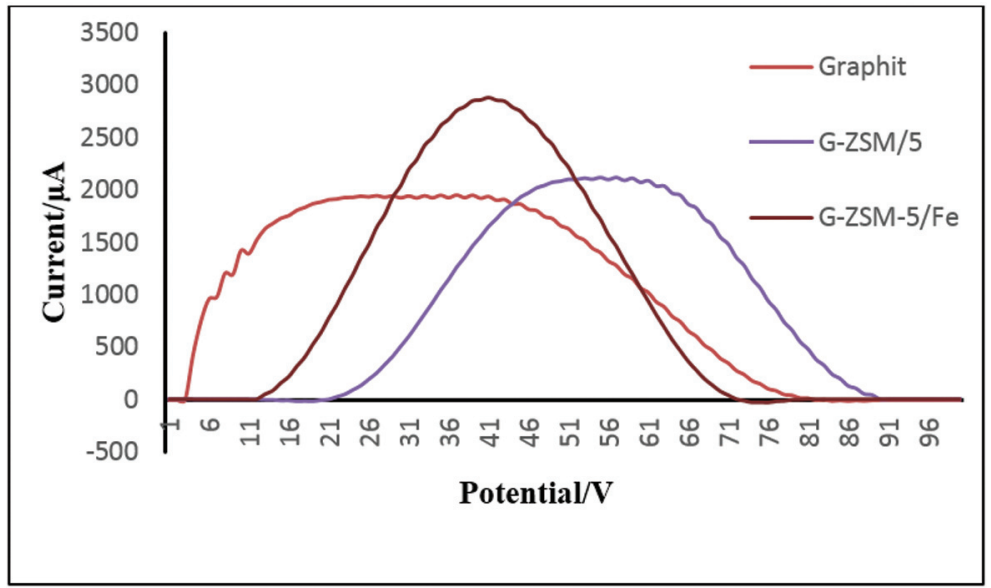

Fig.7. Square wave voltammetry (Sqw) analysis of electrodes prepared in $50 \mathrm{mM}$ phosphate buffered solution (PBS) in room temperature.

According to Figure 7 and 8 , the peak related to the output current and removal of COD during 72hour fuel cell steering, it can be concluded that the produced $\mathrm{G}-\mathrm{Z} / \mathrm{Fe}$ cathode electrode has a higher output efficiency $(21 / 8 \%)$ and COD removal efficiency (36/9\%) than G-Z electrode and simple graphite. The electrochemical analyzes (CV and Sqw) show higher efficiency of this electrode and Figure 9 showed the chemical oxygen demand (COD) for graphen, G-Z and G-Z/Fe electrods..

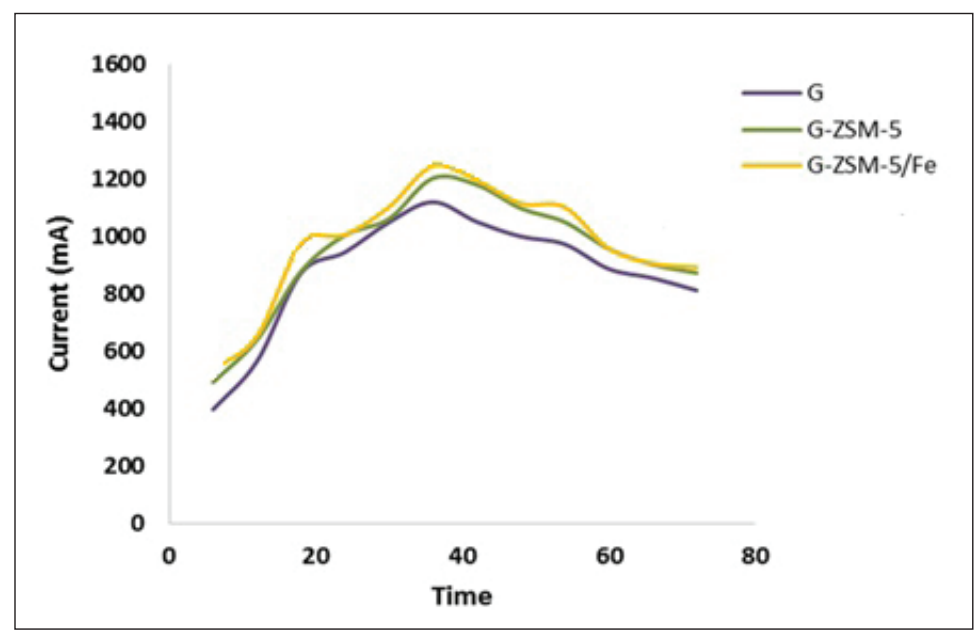

Fig.8. Cell current output per time for G, GZSM-5 and GZSM-5/Fe

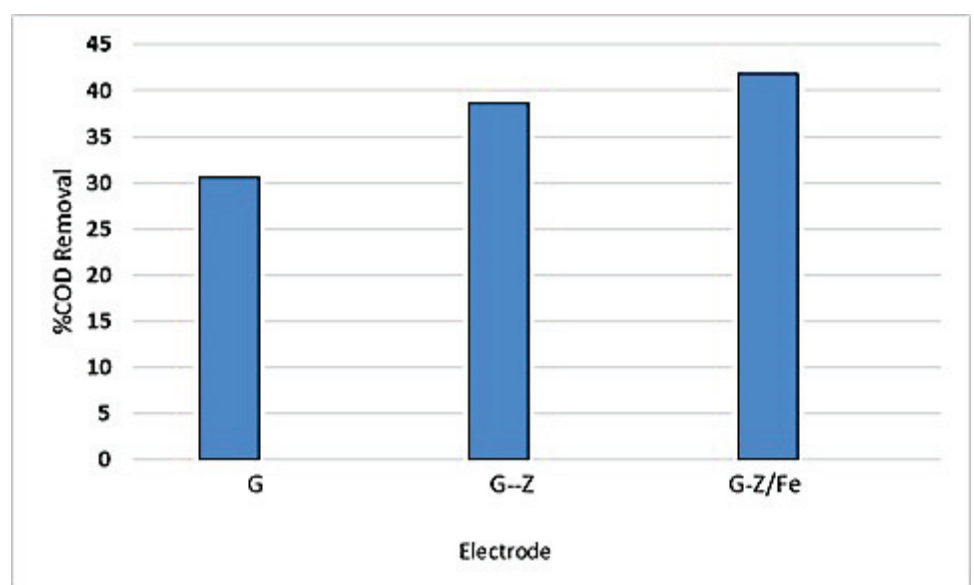

Fig..9. The efficient removal of COD for G,G-Z and G-Z/Fe electrods 


\section{Conclusions}

By procedure, a new microbial fuel cell was made by graphite rod electrodes. The surface of the cathode was modified by ZSM-5 and ZSM-5 functionalized with iron nanocatalyst. All three electrodes $(\mathrm{G}$, G-ZSM and G-ZSM/Fe) were analyzed by square wave and cyclic voltammetry. Both analyses were introduced that the G-Z/Fe electrode had the higher efficiency as compared to others (Fig. 6-7). Experimental results of fuel cell steering was also studied as the Figure 8 and 9 by the G, G-Z and G-Z/ Fe electrode, the results showed that the efficiency of fuel cell output current (I) and residual chemical oxygen demand (\%COD) based on this electrode increased up to $21.8 \%$ and $36.9 \%$, respectively as compared to other graphite electrode. The high efficiency of G-ZSM/Fe nanocatalyst electrode is due to high specific surface area and the presence of iron particles with high electrical conductivity.

\section{Acknowledgments}

The authors would like to thank and appreciate Mr. Mojtaba Azemi Motlagh, Laboratory Technical Manager of Arman Shimi Palayesh Gostar Company, as well as Mr. Hoshang Asadi, Personnel of Chemistry Laboratory at Islamic Azad University, South Tehran Branch, for providing laboratory facilities and equipment.

\section{References}

[1] B. Min, S. Cheng, B.E. Logan, Electricity generation from swine wastewater using microbial fuel cells, J. Water Res., 39 (2005)1675-1686.

[2] Z. Lu, D. Chang, J. Ma, G. Huang, L. Cai, L. Zhang, Behavior of metal ions in ioelectrochemical systems: A review, J. Power Sour., 275 (2015) 243-260.

[3] S.S. Kumar, V. Kumar, Microbial fuel cells (MFCs) for bioelectrochemical treatment of different wastewater streams, Fuel, 254 (2019)115526.

[4] C. Munoz-Cupa, Y. Hu, An overview of microbial fuel cell usage in wastewater treatment, resource recovery and energy production, Sci. Total Energy Prod., 754 (2021) 142429.

[5] W.W. Li, H.Q. Yu, Z. He, Towards sustainable wastewater treatment by using microbial fuel cells-centered technologies, Energy Environ. Sci., 911 (2014)7-24.

[6] S.K. Chaudhuri, D.R. Lovley, Electricity generation by direct oxidation of glucose in mediatorless microbial fuel cells, Nat. Biotechnol., 21(2003)1229-1232.

[7] B. Logan, S. Cheng, V. Watson, G. Estadt, Graphite fiber brush anodes for increased power production in air-cathode microbial fuel cells, Environ. Sci. Tech., 41 (2007) 3341-3346.

[8] X. Gao, Y. Zhang, X. Li, J. Ye, Novel graphite sheet used as an anodic material for highperformance microbial fuel cells, Mat. Lett.,105 (2013) 24-27.

[9] E.Y. Emori, F.H. Hirashima, C.H. Zandonai, C.A. Ortiz-Bravo, N.R.C. FernandesMachado, M.H.N. Olsen-Scaliante, Catalytic cracking of soybean oil using ZSM5 zeolite, Catal.Today, 279 (2017)168-176.

[10] Q. Zhang, G. Liu, L. Wang, X. Zhang, G. Li, Controllable decomposition of methanol for active fuel cooling technology, Energey Fuels, 28 (2014) 4431-4439.

[11] W. Li, G. Li, C. Jin, X. Liu, J. Wang, One-step synthesis of nanorod-aggregated functional hierarchical iron-containing MFI zeolite microspheres, J. Mater. Chem., A, 3 (2015) 14786-14793.

[12] A. Valipour, S. Ayyaru, Y. Ahn, Application of graphene-based nanomaterials as novel cathode catalysts for improving power generation in single chamber microbial fuel cells, J. Power Sour., 327 (2016) 548-556.

[13] G.G. Kumar, C.J. Kirubaharan, D.J. Yoo, A.R. Kim, Graphene,poly(ethylenedioxythiophene), Fe3O4 nanocomposite: An efficient oxygen reduction catalyst for the continuous electricity production from wastewater treatment microbial fuel cells, Int. J. Hydrogen Energy, 41 (2016)13208e13219. 
[14] S.A.A. Yahia. L. Hamadou, M.J. SalarGarcía, A. Kadri, V.M. Ortiz-Martínez, F.J. Hernández-Fernández, A. Pérez de los Rios, N. Benbrahim, $\mathrm{TiO}_{2}$ nanotubes as alternative cathode in microbial fuel cells: Effect ofannealing treatment on its performance, Appl. Sur. Sci., 387 (2016) 1037-1045.

[15] S.S. Manickam, U. Karra, L.W. Huang, N.N. Bui, B.K. Li, J.R. McCutcheon, Activated carbon nanofiber anodes for microbial fuel cells, Carbon, 53 (2013) 19-28.

[16] J. Liu, Y. Qiao, C.X. Guo, S. Lim, H. Song, C.M. Li, Graphene/carbon cloth anode for high-performance mediatorless microbial fuel cells, Bioresour.Technol. Rep., 114 (2012) 275-280.

[17] S. Kalathil, S. Patil, D. Pant, Microbial fuel cells: electrode materials, encyclopedia of interfacial chemistry, Sur. Sci. Electrochem., Elsevier, 309-318, 2018.

[18] M. Jose Salar-Garcia, O. Obata, H. Kurt , K. Chandran, Impact of Inoculum Type on the Microbial Community and Power Performance of Urine-Fed Microbial Fuel Cells, Microorgan., 8 (2020) 1921. http:// doi:10.3390/microorganisms8121921.

[19] L. Yang, Y. Tang, D. Yan, T. Liu, C. Liu, S. Luo, Polyaniline-reduced graphene oxide hybrid nanosheets with nearly vertical orientation anchoring Palladium nanoparticles for highly active and stable electrocatalysis, ACS Appl. Mater. Interfaces, 8 (2016) 169-176.

[20] P. Pattanayak, F. Papiya, V. Kumar, N. Pramanik, P.P. Kundu, Deposition of Ni-NiO nanoparticles on the reduced graphene oxide filled polypyrrole: Evaluation as cathode catalyst in microbial fuel cells, Sustain. Energy Fuels, 3 (2019) 1808-1826.

[21] P. Mishra, R. Jain, Electrochemical deposition of MWCNT- $\mathrm{MnO}_{2} / \mathrm{Ppy}$ nano-composite application for microbial fuel cells, Int. J. Hydrogen Energy, 41 (2016) 22394-22405.

[22] Y. Hou, H. Yuan, Z. Wen, S. Cui, X. Guo, Z. He, J. Chen, Nitrogen-doped graphene/CoNi alloy encased within bamboo-like carbon nanotube hybrids as cathode catalysts in microbial fuel cells, J. Power Sour., 307 (2016) 561-568.

[23] Q. Wena, Y. Wua, D. Cao, L. Zhao, Q.Sun, Electricity generation and modeling of microbial fuel cell from continuous beer brewery wastewater, Bio. Tech.,100 (2009) 4171-4175.

[24] S. Fatemi, A.A. Ghoreyshi, G.H. Najafpour, M. Rahimnejad, Investigation of bioelectricity production in dual chamber microbial fuel cell by mixed culture as active biocatalyst, Iran. J. Biol., 27 (2013) 546-554. 